\title{
Como consumir - com prazer estético - os testemunhos do Holocausto: uma avaliação crítica sobre a Fundação Survivors of the Shoah
}

\section{Adriana Schryver Kurtz}

\section{Resumo}

0 presente artigo reflete acerca do estatuto do testemunho do Holocausto judeu no âmbito de uma cultura de consumo, tendo como objeto de análise 0 projeto original de Steven Spielberg, Survivors of the Shoah, Visual History Fundation, hoje sob a guarda da Universidade da Califórnia do Sul, devidamente rebatizado de USC Shoah Fundation Institute for Visual History and Education. Defenderemos a tese de que mesmo o testemunho e a memória do Terror podem ser estetizados e absorvidos pelo mercado de bens culturais, em um formato saneado e consolador, passível de ser consumido por um público potencialmente massivo. Em que pesem as boas intenções - se é que existem -, Steven Spielberg configura-se como uma discutível "autoridade" midiática - acerca do Holocausto, conformando o imaginário ocidental sobre a memória do genocídio com sua Fundação e o sucesso anterior do filme A lista de Schindler (1993)

\section{Palavras-Chave}

Testemunho. Cultura de Consumo. Holocausto. Survivors of the Shoah. Steven Spielberg.
Adriana Schryver Kurtz I adrianakurtz@terra.com.br Jornalista, doutora e Mestra em "Comunicação e Informação" pela Universidade Federal do Rio Grande do Sul (PPGCOM/Fabico/UFRGS), sob orientação da Prof. Dra. Christa Berger. Professora dos Cursos de Comunicação Social (habilitação em Publicidade e Propaganda) e Design da Escola Superior de Propaganda e Marketing do Rio Grande do Sul (ESPM-RS).

\section{Um singular trajeto do testemunho do Holocausto: de obra estética ao consumo}

Ao introduzir o livro Modernidade e Holocausto (1998), o sociólogo polonês Zygmunt Bauman conta que só teve a dimensão exata do genocídio após sua mulher, Janina, sobrevivente que escapou do gueto de Varsóvia, ter se recolhido durante dois anos para, finalmente, narrar sua própria experiência do Horror. Janina agradecera ao marido por ter suportado sua prolongada ausência. Ela precisava deixar seu testemunho: as memórias de um mundo de trevas que, afinal, não era o mundo de seu esposo. A partir daí, Bauman deu-se conta de que ele, um sociólogo já renomado, compartilhava com boa parte do mundo uma confortável distância daquele evento que parecia já ter "desaparecido da face da terra", permanecendo apenas "na lembrança assombrada e nas feridas jamais cicatrizadas daqueles que destituiu ou feriu" (BAUMAN, 1998, p. 09).

De fato, seriam necessárias várias décadas - a partir da "libertação" dos campos de morte - para que o testemunho sobre o Holocausto 
chegasse a ser um tema presente na cultura ocidental e, mais tarde, um produto cultural para consumo. 0 processo começaria através da literatura - consagrando a chamada "Literatura de Testemunho" - e do trabalho de alguns historiadores particularmente preocupados com uma crítica ao historicismo e à (re)valorização da questão da memória, sobretudo da intersecção entre memória individual e coletiva. Esse movimento parte da releitura mais atenta de Walter Benjamin e terá entre seus principais teóricos nomes como Maurice Halbwachs, Saul Friedländer, Yosef Yerushalmi, Vidal-Naquet, Annette Wieviorka, Shoshana Felman, Pierre Nora - autor do clássico Os assassinos $d a$ memória -, entre outros. Em menor ou maior grau, todos defenderam um trabalho em conjunto entre historiografia e memória, como bem destacou Márcio Seligmann-Silva em sua obra História, memória, literatura: o testemunho na era das catástrofes (2003).

0 testemunho deve ser compreendido, dirá Seligmann-Silva, "tanto no seu sentido jurídico e de testemunho histórico" - que corresponde à tradição do testimonio das vítimas das ditaduras na América Latina, com ênfase para os aspectos de denúncia e reportagem -, "como também no sentido de 'sobreviver', de ter-se passado por um evento-limite, radical, passagem essa que foi também um 'atravessar' a morte" (SELIGMANNSILVA, 2003, p. 08). Neste último sentido, ligado à Literatura de Testemunho da Shoah, ocorre uma inflexão importante, pois a relação entre a linguagem e 0 'real' passa a ser problematizada. Se 0 testemunho do Terror transforma-se em arte literária - até mesmo para fugir à terrível literalidade de um universo cuja violência era humanamente inacreditável e indescritível -, 0 fato é que também será absorvido, lentamente, pela esfera do consumo. Afinal, como já mostraram Adorno e Horkheimer desde a crítica à Indústria Cultural, em meados dos anos 40, 0 destino das artes e da cultura seria 0 de fundirse ao da economia, passando a ser tratadas, a rigor, como qualquer outra mercadoria.

Assim, o próprio Holocausto, bem como a tradição de testemunho que ensejou, não deixaria de constituir, ao longo das últimas seis décadas, diferentes modalidades de "produtos culturais". E como lembrou Don Slater (2002, p. 27), um analista não exatamente crítico, vivemos uma cultura de consumo exatamente a partir do momento em que "as práticas sociais e os valores culturais, ideias, aspirações e identidades básicas" passam a ser "definidas e orientadas em relação ao consumo, e não a outras dimensões sociais". Uma vez que os valores derivados do "reino do consumo" invadem outros domínios da ação social, "a sociedade moderna é in toto uma cultura do consumo, e não apenas especificamente em suas atividades de consumo" (SLATER, 2002, p. 32). Eis o panorama inevitável do que Fredric Jameson (1995) denomina de lógica cultural do capitalismo tardio ou "dominante cultural pós-moderna". 
Este artigo pretende se deter num caso pontual de produção e consumo de testemunhos acerca do Holocausto e da memória que alimenta essa tradição: o projeto Survivors of the Shoah: Visual History Fundation, concebido por Steven Spielberg logo após o sucesso mundial de $A$ Lista de Schindler (1993) e hoje sob a guarda da University of Southern California, mantenedora oficial do acervo, rebatizado com o nome mais "politicamente correto" e pedagógico de USC

\section{Shoah Fundation Institute for Visual History}

and Education. Ainda que se leve em conta as boas intenções de seu idealizador e da instituição que atualmente administra 0 acervo da Fundação, o material não deixa de ser suscetível de incômodos questionamentos, sob a luz da ética e da própria consideração às características intrínsecas ao testemunho.

De fato, desde o começo, as críticas recaíram sobre a orientação original do projeto no trato dos relatos dos sobreviventes, feitos a partir de um roteiro previamente estabelecido, cuja natureza, intenção e resultados podem ser questionados a partir de teóricos tão díspares quanto Theodor Adorno (1991; 1993), Reyes Mate (2003), Roney Cytrynowicz (2000), Arturo Lozano Aguilar (2001), além do cineasta judeu Claude Lanzmann (1997 apud CANGI, 2003) e o sobrevivente Primo Levi (2004). Levando em consideração as exigências estéticas, morais e éticas desses autores, é possível defender a tese de que o material da Fundação, contra a sua própria intenção original, acaba por comprometer
- ou mesmo trair - o testemunho enquanto possibilidade histórica, bem como a memória do próprio evento que se pretende preservar, maculando seu conteúdo de verdade, para usar uma expressão cara a Theodor Adorno.

As desconfianças com o projeto original do acervo de testemunhos dos sobreviventes do Holocausto, concebido na primeira metade dos anos 90 e denominado Survivors of the Shoah, Visual History Fundation, tem ainda um outro - e forte - argumento: a própria postura e intenções de seu idealizador, o cineasta Steven Spielberg. Como já tivemos a oportunidade de ressaltar em outro estudo, dedicado à análise dos mais de 15 anos de realização (e sucesso) de sua obra máxima, A Lista de Schindler, 0 diretor norte-americano tomou para si o lugar de "especialista" ou mesmo de porta-voz das vítimas da Shoah. Mais do que isso, Spielberg, ao construir uma significativa obra audiovisual ligada ao Holocausto, apresenta-se, no âmbito da cultura de consumo norte-americana e mundial como uma modalidade de curador, se pudermos usar tal expressão, da representação do testemunho e da memória das vítimas e sobreviventes do genocídio nazista. Note-se que estamos assumindo representação, seguindo o conceito oriundo da História Cultural, como "[...] presentificação de um ausente, como um apresentar de novo, que dá a ver uma ausência", para usar as palavras da historiadora Sandra Pesavento (2003, p. 40). 
Certamente outros cineastas buscaram

se apropriar - em maior ou menor grau desse papel, e o exemplo mais conhecido e polêmico, especialmente no âmbito europeu, é 0 do cineasta francês Claude Lanzmann. Mas, ao contrário de Spielberg, que se deu conta de suajudeidade somente às vésperas da campanha promocional de A Lista de Schindler, Lanzmann, ao longo de toda a sua vida, não apenas se colocou no mundo como um artista judeu: ele milita ativamente, inclusive no espinhoso papel de defensor do Estado de Israel, e pode-se acusá-lo de tudo, menos de falta de comprometimento radical e coerência em sua trajetória (e na sua obra fílmica).

Além disso, diferentemente da produção de Spielberg, que usa as mesmas fórmulas para arrancar lágrimas aliviadas em filmes de extraterrestres, tubarões, dramas familiares do Sul racista, resgates de soldados na Segunda Guerra Mundial ou matança industrial de judeus em plena Europa do século XX, o filme referencial de Lanzmann sobre 0 tema, 0 monumental documentário Shoah (1974-1985), é considerado pela crítica especializada como uma obra prima e definitiva sobre 0 extermínio nazista, ainda que pouco conhecida do grande público. Isso, aliás, já denota uma questão fundamental sobre o consumo de um produto cultural cujo tema é, a rigor, tão indigesto: os mais respeitados e esclarecedores filmes não chegam a tocar na popularidade e na visibilidade midiática daqueles, vistos com desprezo ou restrições, certamente mais apropriados ao entretenimento das multidões, aos quais podemos acrescentar, além de $A$ Lista de Schindler, obras como Holocaust (1978) e, especialmente, A vida é bela (1997), do clown narcisista Roberto Benigni.

0 sucesso desses títulos exemplares - bem como as cifras decorrentes de um consumo massivo em todo o planeta - aponta para 0 fenômeno conhecido como "americanização do Holocausto"1, o que alimentou, de forma natural, críticas ácidas acerca de uma verdadeira "Indústria do Holocausto", termo provocador de Finkelstein (2001). Note-se que após ofrisson até certo ponto inesperado do filme sobre o nazistoide subitamente transformado em humanista e salvador de judeus, o próximo passo de Spielberg no sentido de assumir o monopólio sobre a representação - e a "história" - do Holocausto seria efetivado com o projeto de sua Fundação Survivors of the Shoah, Visual History Fundation, que colheu relatos de sobreviventes em todas as partes do mundo durante os anos 90 , inclusive no Brasil.

A América do Norte, disse Finkelstein (2001), assumiria o Holocausto como um dos relatos fundadores de sua identidade. Spielberg tem um papel fundamental nesse processo. 0 destino dos Schindlerjuden (os "judeus de Schindler") elevaria 0 diretor infantiloide a um inusitado e novo status. A estratégia implicava a busca de um tema de ampla aceitação, a minimização de sua carga explosiva e sua posterior transformação em algo politicamente correto, que acarretasse em maior estremecimento emotivo e menor reflexão sobre os fatos e suas consequências. Assim, como ressaltou Aguilar (2001, p. 27), a experiência mais demolidora para a moderna civilização ocidental acabou assimilada a uma moda moralizante, apta para difundir uma mensagem de otimismo e redenção. 
Parte desse material acabou sendo utilizada no documentário Sobreviventes do Holocausto (1996), filme dirigido, ao menos oficialmente, por Allan Holzman e produzido por Spielberg. 0 sucesso performático do projeto de arquivamento da memória e testemunho dos sobreviventes em escala planetária, entretanto, mostrou-se prejudicial para o seu idealizador. 0 trabalho da Fundação e o papel central do cineasta norteamericano foram criticados de forma implacável, o que levaria Spielberg a recuar e doar o material para a University of Southern Califórnia. 0 desligamento, por assim dizer, da figura até então central de um dos mais famosos produtores de sucessos melodramáticos de Hollywood seria efetivado com a mudança no nome do acervo. Mas 0 mesmo não pode ser dito sobre o conteúdo desses documentos, como veremos em breve.

Ocorre que há diferentes formas de se trabalhar um conteúdo testemunhal. As mais de nove horas de duração do documentário francês Shoah trazem apenas o testemunho na sua forma mais pura e ideal; ou seja, depoimentos dos sobreviventes no tempo presente, sem nenhuma imagem de arquivo (propícia ao gozo mórbido do sofrimento) ou qualquer recurso adicional dramático. Vemos, sobretudo, rostos e vozes, num claro trabalho de história oral que se contrapõe ao "roteiro" das narrativas coletadas para a Fundação spielberguiana Survivors of the Shoah, que, como o próprio nome destaca, cria uma categoria um tanto híbrida e frágil: a de uma "história visual". Em 1997, em entrevista concedida ao jornal argentino Página 12,

Lanzmann detonaria uma pesada artilharia

contra o projeto memorialístico spielberguiano

Há uma sorte de inflação da memória, [...] além disso, ocupam-se dos sobreviventes e os sobreviventes estão muito contentes de poder contar sua história pessoal. Não se esqueça de que os sobreviventes de "Shoah" são sobreviventes muito especiais. Não se pode quase chamálos de sobreviventes. Vivem da morte. E não testemunham por si mesmos, senão pelos mortos. São os porta-vozes dos mortos. Há gente ali que trabalhou até o último grau do processo de destruição e poderia ter sido assassinada e sobreviveu por uma combinação de sorte, milagre, coragem ou o dedo de Deus. "Shoah" não é um filme sobre sobreviventes. Estas pessoas em "Shoah" jamais dizem "eu", nunca contam sua história pessoal, nunca dizem como escaparam. Elas não queriam contá-lo e eu não queria perguntar-lhes sobre isso. Não me interessava, porque "Shoah" é um filme sobre a morte, sobre a radicalidade da morte, e não um filme de aventuras sobre uma fuga (1997 apud CANGI, 2003, p. 160).

Um recuo no tempo nos fará lembrar que 0 "filme de aventuras" de Spielberg, recuperou e ampliou nos Estados Unidos um clima de comoção que havia sido aberto cerca de 15 anos antes com a telessérie "Holocaust" (1978). As reações a

"Lista de Schindler" incluíram alguns equívocos e excessos detectados por Aguilar (2001), ainda que tenha reagendado um tema importante. Na época, grupos de educadores consideraram a narrativa como "um antídoto contra o racismo", conectando de forma simplista a mensagem pró-judaica com a luta contra o racismo norte-americano. Houve, como seria de esperar, a participação especial de grandes personalidades nacionais e midiáticas: 0 
presidente Bill Clinton, após ver a estreia mundial da película, a convite do próprio Spielberg, interpretou a narrativa, em um ato de primeiro de dezembro, Dia Mundial de Luta Contra a AIDS, como uma forma de compreender "a natureza do sofrimento humano, sua apropriada resposta e a dolorosa diferença entre as pessoas que perdem a esperança e as forças diante daquelas que, apesar de tudo, as conservam". Já a apresentadora Oprah Winfrey, ícone da comunidade negra dos EUA (os "afro-descendentes", para os xiitas politicamente corretos), afirmou que ver o filme havia feito dela uma pessoa melhor. Assim, o ano de 1993 poderia ser considerado como "0 ano do Holocausto" nos Estados Unidos. Em Washington seria inaugurado o United States Holocaust Memorial Museum, enquanto escolas de formação elementar de alguns Estados incluíam uma disciplina sobre o Holocausto - entre outros genocídios, naturalmente -, devidamente ilustrado pela "Lista de Shindler" (AGUILAR, 2001, p. 29-30).

Entretanto, como o químico italiano e sobrevivente de Auschwitz, Primo Levi, nos ensinou em seus relatos e análises da Shoah, a imensa maioria dos que sobreviveram era formada pelos chamados "privilegiados", prisioneiros que obtiveram alguma espécie de privilégio "submetendo-se à autoridade do campo" (2004, p.15). Estes, diria ainda Levi, não testemunharam sua história ou - quando o fizeram - deixaram relatos lacunosos, distorcidos ou totalmente falsos. Caso, diga-se, em que se encaixam, em algum grau, potencialmente, os simpáticos idosos que vemos desfilar no material da Survivors of the Shoah, Visual History Fundation e de seu "piloto" fílmico, Sobreviventes do Holocausto. Ora, tal passado - e sua zona cinzenta - não é compatível com a concepção spielberguiana de testemunho de seus personagens-vítimas, necessariamente lineares e sem nuances (leia-se irretocavelmente "bons" e "inocentes"). É lógico que, para o grande público (leigo e pouco consciente da brutal realidade dos campos), esse passado omitido das memórias e dos testemunhos, fruto daquela terrível zona cinzenta, será necessariamente chocante e comprometedor no âmbito da empatia com os personagens do drama². Aí começam os problemas no que diz respeito à verdade histórica.

\section{Estetização, Memória e Esquecimento no processo de americanização da Shoah}

Lembremos um dos ensinamentos do historiador Jacques Le Goff: tornar-se "senhores da memória e do esquecimento" é uma preocupação vital

Para quem é familiarizado com os testemunhos dos sobreviventes e os relatos históricos sobre o massacre a que foram submetidas as vítimas, torna-se bastante compreensível que tenham sido, em algum grau, pressionados a ponto de buscarem formas de sobrevivência que incluíram diferentes modalidades de submissão à autoridade. Mas para um público massivo, caracterizado por uma frágil noção histórica e pelo desconhecimento dos testemunhos que foram mais fundo no resgate do Horror, eventuais formas de colaboração das vítimas no seu próprio processo de destruição tornam-se incompreensíveis. Assim, a representação dos eventos acaba por sujeitar as vítimas a mais uma forma de violência: o julgamento apressado e pouco ponderado sobre o comportamento (e é claro, o caráter) dos sobreviventes. 
das classes, dos grupos e dos indivíduos que dominaram e dominam as sociedades históricas (2003, p. 422). Se a apreensão da memória é sempre dependente do ambiente social e político, resta entender as circunstâncias que confluíram para que Spielberg invadisse o imaginário mundial com seu projeto pós-moderno de coleta de testemunhos. 0 processo seria embalado pelo contexto de "americanização do Holocausto" e pelo sucesso global de seu relato ficcional sobre 0scar Schindler.

\begin{abstract}
A Lista de Schindler fixou de maneira determinante a memória da Shoah para as presentes e futuras gerações; laureou a carreira de Spielberg com a bendição de seis 0scars, entre eles a de melhor diretor e melhor película; gerou uma moda paralela pelo testemunho, o Holocausto e suas consequências moralizantes (adaptadas a muitos diferentes contextos e sempre em busca do consenso das massas), na realidade muito parecida àquela que desatou por extraterrestres, tubarões ou dinossauros (AGUILAR, 2001, p. 34).
\end{abstract}

Pois foi exatamente na esteira desse boom que Spileberg lançou Survivors of the Shoah:

Visual History Fundation. A Fundação colocou em ação centenas de pesquisadores pelo mundo afora a buscar o relato - um relato padrão e com um devido "enquadramento da memória" - dos sobreviventes, num momento em que grande parte das testemunhas estava chegando mais perto de seu desaparecimento. Como bem notaria Eric Rentschler, a relação visceral e histórica que o cinema sempre manteve com a propaganda (ideológica e/ ou política), reconfirmaria a Alemanha nazista e Hollywood como "os mais poderosos e ressoantes protagonistas que têm alimentado a imaginação das massas no século XX" (2000, p. 14). Se pensarmos na colocação de um Primo Levi, de que a experiência dos campos da morte fizera emergir duas espécies de categorias de seres humanos: a dos que se salvam e a dos que afundam, veremos que Spielberg promoveu, totalmente à sua maneira, esta constatação. 0 ínfimo número dos judeus de Schindler - pouco mais de mil pessoas -, e os sobreviventes entrevistados pela fundação, se comparados as seis milhões de vítimas do Holocausto "real", ganharam o direito de viver e a plena visibilidade no universo da representação.

Nos dois exemplos, entretanto, estamos longe da literalidade terrível dos campos de concentração e extermínio e dos verdadeiros sujeitos/"personagens" do Holocausto, que passam rapidamente pelas telas. Trata-se dos chamados Muselmann ou "muçulmanos", espécie de gíria dos campos que designavam as centenas de milhares de homens e mulheres de olhar vazio e inerte, prestes a morrer, numa média máxima de três meses após a "internação". Como então a ofensa perpetrada pelos algozes nos guetos e campos da morte pode ser redimida pela milagrosa e, inexplicavelmente, generosa intervenção do charmoso 0scar Schindler ou pelas imagens finais dos testemunhos da Fundação Shoah, quando os sobreviventes são instados a mostrar 
uma espécie de happy-end e a apresentar as suas (novas) famílias e descendentes?

Também não parece haver o justo espaço no projeto testemunhal de Spielberg para 0 ressentimento, aquela "forma moral de protesto contra 0 esquecimento, a reivindicação da vigência do olhar da vítima" de que fala Reyes Mate (2003). É de se perguntar se, nas imagens belas e algo fake de A Lista de Schindler, assim como nas cenas familiares dos sobreviventes que alimentam 0 acervo multimídia de Survivors of the Shoah, veremos o mundo com o olhar - inclusive ressentido - das vítimas. Resta a suspeita de que a memória engendrada por Spielberg possa estar longe daquele imperativo desejado por Reyes Mate, "o papel da memória é devolver-nos o olhar do oprimido. Ver o mundo com os olhos das vítimas" (2003, p. 111). Como disse, definitivamente, Adorno (1991, p. 65): "dessas vítimas prepara-se algo, obras de arte, lançadas à antropofagia do mundo que as matou", uma vez que, "pelo princípio de estilização estética e até pela prece solene do coro, o destino imponderável se apresenta como se tivesse tido algum sentido algum dia; é sublimado, e tira-se um pouco do seu horror". Acerca das testemunhas de Spielberg e de seu imaginário do Holocausto, pode-se ainda invocar o Aforismo 25 de Minima Moralia. No texto, intitulado Ninguém se lembre deles, o filósofo acusa: "0 que não está reificado e não pode ser contado nem medido, deixa de existir. Mas, não bastasse isso, a reificação estende-se ao seu próprio contrário, à vida que não pode ser imediatamente atualizada; ao que só subsiste como pensamento e lembrança". Assim, a vida profanada "é ainda por cima arrastada sobre o carro triunfal dos estatísticos unidos, e o próprio passado não está mais a salvo do presente, que o condena mais uma vez ao esquecimento no instante em que o recorda" (ADORNO, 1993, p. 39).

0 espírito, por assim dizer, de tal monopólio de representação também será contestado por historiadores da Shoah. Roney Cytrynowicz (2000) chamará a atenção para as consequências do tratamento midiático sobre eventos historicamente relevantes como o extermínio industrial dos judeus europeus sob Hitler. "Uma certa hegemonia do discurso da memória, como o projeto Spielberg, por exemplo, aprisiona a memória em um imenso molde de produção após o qual dificilmente se poderá reconhecer nela a experiência subjetiva de destruição". Trata-se, como parece evidente, de uma memória "armazenada e oferecida como indústria de entretenimento" e, enquanto "memória de entretenimento", ela certamente em nada contribui "nem para a dignidade dos sobreviventes nem para a compreensão do Holocausto", fustiga Cytrynowicz (2000, p. 204).

De fato, o incômodo no material da Fundação Shoah pode ser vislumbrado perfeitamente no documentário que resultou do início da coleta 
de depoimentos, Sobreviventes do Holocausto (1996), da dupla Holzman/Spielberg ${ }^{3}$. 0 filme é rigorosamente preso a uma ordem de apresentação da narrativa clássica. Começamos lentamente com os fatos, que vão num crescendo, e depois do clímax temos, como em qualquer boa história emotiva e lacrimosa, o happy end. Aqueles homens e mulheres que contaram tristes histórias e choraram copiosamente parecem ao final aliviados, exibindo suas famílias com orgulho sincero, todos cheios de sorrisos em frente às câmeras da Fundação. A mensagem parece dizer, no silêncio, sempre a mesma ladainha: foi horrível, mas acabou e eu estou aqui, com meus numerosos filhos e netos, em minha nova vida. É marcante uma patética declaração de um simpático sobrevivente que diz algo como: "Hitler e seus canalhas tentaram me matar mas eu fui mais esperto e estou aqui, são e em meio aos meus familiares". Quanto a essa sucessão mecânica de imagens das famílias renovadas, lembremos de Todorov (2002, p. 195): "A memória pode ser tornada estéril por sua forma: porque o passado, sacralizado, não nos evoca nada além dele mesmo; porque o mesmo passado, banalizado, nos faz pensar em tudo e em qualquer coisa".

0 material que Spielberg acabou por entregar à University of Southern Califórnia já estava, basicamente, finalizado. A concepção dos depoimentos é instrutiva: a gravação das entrevistas oscilava entre duas e cinco horas de duração e seguia três coordenadas cronológicas da vida do sobrevivente: 0 período anterior à perseguição; a fase efetiva do Horror, incluindo perseguição, deportação, vida nos campos e regresso; e, finalmente, a reinserção na vida do pós-guerra até a atualidade. De forma geral, essas três fases têm a duração, respectivamente, de $20 \%, 60 \%$ e $20 \%$ do testemunho. "Por sua própria estrutura, estas entrevistas já eludem a questão do extermínio sistemático", nota Lozano Aguilar. "A relevância das memórias dos sobreviventes parte de que estes são os únicos capacitados para testemunhar uma parte do sofrimento dos que pereceram. Esses testemunhos, portanto, só podem ser lidos como uma pequena sinédoque do sofrimento suportado por milhões de mortos" (2001, p. 38-9).

0 autor avalia sem concessões as implicações do método spielberguiano. A centralidade que deveria ocupar 0 assassinato massivo é atenuada e substituída pelo modo como a persecução nazi afetou a vida do sobrevivente e como este conseguiu evitá-la. Assim, o peso dos mortos fica reduzido a sua mínima expressão: ainda que ao final da entrevista o depoente enumere seus familiares assassinados, evocando a última vez que os viu e como morreram (se o sabe);

0 filme é marcado por um alto grau de ficcionalização dos testemunhos e por evidente vocação propagandística: imagens, músicas, texto em off e um certo padrão que condiciona os depoimentos, afirmam os EUA como o país de acolhida dos sobreviventes e sacralizam o Estado de Israel, embalado por uma mistura de sionismo e religiosidade judaica subitamente despertada em Spielberg. 
ao encerrar a entrevista, ele será convidado a oferecer uma consigna moral e mostrará seus filhos e netos, seus descendentes. Resulta desse expediente que 0 vácuo, por assim dizer, dos familiares mortos parece preenchido com os membros da nova família, o que converte os falecidos em meros antecedentes biológicos do narrador. É patético o comentário de Spielberg sobre esse encerramento: "isto demonstra que é certo o fato de que salvando uma vida pode salvar-se ao mundo". Mais desconcertante é a emenda de Ben Kingsley4: "e 0 vazio que deixaram todos os que morreram" (1996 apud AGUILAR, 2001, p. 39).

A consequência mais funesta do projeto de Steven Spielberg ainda não é a própria reificação da memória. Há algo pior: sua intenção de elevar-se acima das características da memória e converter-se em História. Há que se perguntar até que ponto relatos testemunhais edificantes podem incorrer num processo de naturalização da história. Lembremos que o próprio nome da Fundação aponta para isso e, aliás, sequer fala em memória. 0, diretor de investigação da Survivors of the Shoah, Ari Zev, por sua vez, ao relembrar o sistema acumulativo perseguido pela Fundação original informaria a existência de três categorias para as entrevistas recolhidas: "jornalística, terapêutica e histórica". 0 objetivo, segundo declarou na época, era o de "servir-se do melhor de cada uma delas" (ZEV [2000?] apud AGUILAR, 2001, p. 39).

0 sistema multimídia utilizado para armazenar os testemunhos também é discutível: uma vez transferidos para a base de dados, os testemunhos são fragmentados em itens particulares que podem ser consultados pelo interessado independentemente do resto de suas memórias. 0 que preocupa os críticos está muito além do fato óbvio de que as novas gerações, conformadas pela tecnologia computacional, não têm o hábito de pesquisar temas muito longos, acostumados como estão com a rapidez e a possibilidade de navegar a partir de múltiplos links. Pode-se indagar até que ponto e em que medida um acervo configurado nesses termos se diferencia daquela "indústria da experiência" ${ }^{\text {q } q u e}$ Lipovetsky ressalta em seu ensaio sobre a sociedade do hiperconsumo, no contexto de "um novo capitalismo centrado não mais na produção material, mas no divertimento e nas mercadorias culturais" (LIPOVETSKY, 2007, p. 62). Pois,

0 ator inglês interpretou o terceiro personagem em importância do filme A Lista de Schindler, o contador que auxilia nos negócios do industrial alemão. A frase é um verso do Talmud 3/4 "Quem salva uma vida salva ao mundo inteiro" 3/4 que será inscrita numa aliança de ouro que Schindler ganhará de seus protegidos ao final do filme. A progressiva amizade e contato entre os judeus e 0 industrial será a força motriz para sua conversão ética.

"Além dos equipamentos e dos produtos acabados, as indústrias de lazer trabalham hoje com a dimensão participativa e afetiva do consumo, multiplicando as oportunidades de viver experiências diretas", lembra Gilles Lipovetsky. Na terceira fase da sociedade de consumo, a civilização do objeto foi substituída por uma "economia da experiência", que incluiu lazeres, espetáculos, jogos, turismo e distração (2007, p. 63) 
como sugeriu Bauman, a cultura da sociedade de consumo - por suas características intrínsecas - "envolve sobretudo o esquecimento, não 0 aprendizado". Cáustico, o sociólogo nos adverte: "é um bocado divertido viver uma experiência que não se sabia que existia e um bom consumidor é um aventureiro amante da diversão" (BAUMAN, 1999, p. 90).

Na telas do sistema da Fundação agora sob nova guarda, surge a imagem do sobrevivente narrando suas experiências, as quais, por sua vez, são ilustradas com mapas e imagens documentais dos campos de concentração, das cidades onde estavam instalados, entre outras informações correlatas. Durante o relato e à medida que surgem distintos temas, lugares ou pessoas, 0 sistema oferece links através dos quais aquele que consulta pode conectar com as narrações de outros sobreviventes. "Todo esse desenvolvimento tecnológico afeta de maneira determinante os testemunhos, que abandonam sua individualidade para engrossar uma enciclopédia multimídia do extermínio dos judeus na Europa", fustiga Lozano Aguilar (2001, p. 40). Ele faz notar que a digitalização dos relatos e sua forma de organização acabam por atentar seriamente contra uma das características fundamentais da memória, a saber: 0 relato unitário e coerente que converte 0 passado em experiência. Assim, a disposição dos testemunhos busca a informaç̧ão contida em cada um deles como se tudo se tratasse de cartografar a Shoah, de substituir os estudos históricos por uma acumulação de informações dispersas, carentes da organização e da hierarquia que presidem a escritura científica, trocada aqui pela emotividade das memórias.

À parte a fascinação que busca a tecnologia $\mathrm{e}$ a amenidade de um sistema audiovisual, duvidamos seriamente dos logros da Visual History Foundation. Como documento histórico é de um valor muito limitado por três motivos fundamentais $^{6} . .$. [... Como recolhida de memórias seu fracasso seja talvez mais rotundo, já que 0 sistema consegue eliminar a característica ética da memória. A memória tinha como próprio a reintrodução do humano na sucessão cronológica de acontecimentos e a constatação da crise da civilização ocidental por haver extirpado deste progresso a humanidade que 0 devia guiar. 0 resultado final da Survivors of the Shoah, Visual History Fundation, ainda que com efeitos muito menos perniciosos, soma-se a esta desumanização ao esvaziar a memória da experiência contida em cada relato, convertendo-a em mera base de dados (AGUILAR, 2001, p. 41).

As memórias do Holocausto e de suas vítimas, oferecidas com maior ou menor grau de sofisticação estética e tecnológica para a presente e as futuras gerações, enquanto bens de consumo, produzidas dentro da sua lógica e com suas marcas, assim, são passíveis de reflexão. 0 acervo da USC Shoah Fundation Institute for Visual History and Education, construído

Os três motivos são: os acontecimentos não podem ser abarcados em toda a sua extensão, pois o ponto de vista dos sobreviventes é realmente muito restringido; a impossibilidade de contrastar a fidelidade dos testemunhos (para não falar nas imprecisões causadas pelas fragilidades de uma memória traumática); a escritura subjetiva e pessoal sem demasiadas cautelas no momento de fixar o sucedido em termos descritivos mais precisos (AGUILAR, 2001, p. 41) 
nos moldes de seu idealizador original, parece contrariar aquele ideal defendido por Jeanne Marie Gagnebin: "inventar resistências coletivas ao processo coletivo de alienação, em vez de reforçá-lo por pequenas soluções privadas de consumo" (2006, p. 115). 0 filósofo judeu alemão Theodor Adorno, que ao contrário de seis milhões de contemporâneos, ficaria vivo para ver o Holocausto transformar-se em um produto cultural agradavelmente digerível, anotaria no Aforismo 30 de Minima Moralia:

[...] progresso e barbárie estão hoje, como cultura de massa, tão enredados que só uma ascese bárbara contra esta última e contra 0 progresso dos meios seria capaz de produzir de novo a não-barbárie. Nenhuma obra de arte, nenhum pensamento tem chance de sobreviver, a menos que encerre uma recusa à falsa riqueza e à 'produção-de-primeira-classe', ao filme em cores e à televisão, aos magazines milionários $\mathrm{e}$ a Toscanini. Os meios mais antigos, não programados para a produção em massa, adquirem uma nova atualidade: a atualidade do não-capturado e da improvisação. Só eles conseguiriam escapar à frente única entre os trustes e a técnica (ADORNO, 1993, p. 43).

\section{Referências Bibliográficas}

ADORNO, Theodor W . Minima Moralia: reflexões a partir da vida danificada. São Paulo: Ática, 1993.

Notas de Literatura. Rio de Janeiro: Tempo Brasileiro, 1991.

AGUILAR, Arturo Lozano. Steven Spielberg: La lista de Schindler - estudio crítico. Barcelona: Paidós Ibérica, 2001.

BAUMAN, Zigmunt. Globalização: as consequências humanas. Rio de Janeiro: Jorge Zahar, 1999.
Modernidade e Holocausto. Rio de Janeiro:

Jorge Zahar, 1998.

CANGI, Adrián. Imagens do horror: paixões tristes. In: SELIGMANN-SILVA, Márcio. História, memória, literatura: 0 testemunho na era das catástrofes. Campinas, SP: Editora da UNICAMP, 2003. p. 141-71.

CYTRYNOWICZ, Roney. As formas de lembrar e a história do Holocausto. In: MILMAN, Luis; VIZENTINI, Paulo (orgs.). Neonazismo, negacionismo e extremismo político. Porto Alegre: UFRGS; CORAG, 2000. p. 195- 206.

FINKELSTEIN, Norman G. A indústria do Holocausto: reflexões sobre a exploração do sofrimento dos judeus. 4. ed. Rio de Janeiro: Record, 2001.

GAGNEBIN, Jeanne-Marie. 0 rastro e a cicatriz: metáforas da memória. In: . Lembrar escrever esquecer. São Paulo: 34, 2006. p. 107-118.

JAMESON, Fredric. As marcas do visível. Rio de Janeiro: Graal, 1995.

LE GOFF, Jacques. História e memória. 5. ed. Campinas:Unicamp, 2003.

LEVI, Primo. É isso um homem? Rio de Janeiro: Rocco, 1988.

Os afogados e os sobreviventes: os delitos, os castigos, as penas, as impunidades. 2. ed. São Paulo: Paz e Terra, 2004.

LIPOVETSKY, Gilles. A felicidade paradoxal: ensaio sobre a sociedade de hiperconsumo. São Paulo: Companhia das Letras, 2007.

MATE, Reyes. En torno a una justicia anamnética. In: MARDONES, José María; (eds.). La ética ante

las víctimas. Barcelona: Anthropos, 2003. p. 100 - 125.

PESAVENTO, Sandra Jatahy. História \& história cultural. Belo Horizonte: Autêntica, 2003. (Coleção História \& Reflexões, 5)

RENTSCHLER, Eric. El pasado que no quería desaparecer. In: et al. . Alemania desde la 
perspectiva de Roberto Rossellini, Alain Resnais e

Jean-Luc Godard: tres cineastas europeus europeos y su visión de la realidade alemana. München: GoetheInstitut, 2000. p. 01-20.

SELIGMANN-SILVA, Márcio. História, memória, literatura: 0 testemunho na era das catástrofes.

Campinas: UNICAMP, 2003.

SLATER, Don. Cultura de consumo \& Modernidade.

São Paulo: Nobel, 2008.

TODOROV, Tzvetan. Memória do mal, tentação do bem. São Paulo: Arx, 2002.

\section{Filmografia}

A LISTA de Schindler. Direção: Steven Spielberg.

EUA: Universal Pictures; Amblin Entertainment, 1993. 1 filme (195 min.), son., col. e P\&B. 35mm. Título original: The Schindler's List. Leg. Português.

HOLOCAUSTO. Direção: Marvin J. Chomsky. Produção: Pia Arnold, Robert Berger, Herbert Brodkin. EUA: Titus Productions Inc., 1978. 1 filme - série para TV (475 min.), son., col. e P\&B. Título original: Holocaust. Dublado.

SHOAH. Direção: Claude Lanzmann. França: Historia; Les Films Aleph; Ministère de la Culture de la republique Française, 1974-1985. 1 filme - duas partes - (544 min.), son., col. 35mm. Leg. espanhol.

SOBREVIVENTES do Holocausto. Direção: Allan Holzman. Produção: Steven Spielberg, June Beallor, James Moll e Jacoba Atlas. EUA: Home Entertainment, 1996. 1 filme (70 min.), son., col. e P\&B. 35mm. Título original: Survivors of the Holocaust. Leg. português. 


\section{How to consume - with aesthetic pleasure - the testimonies of the Holocaust: a critical evaluation about Survivors of the Shoah foundation}

\section{Abstract}

The present article is a reflection about the statute of the Jewish Holocaust's testimony in the scope of a consumption culture, having, as the analysis object, Steven Spielberg's original project Survivors of the Shoah, Visual History Foundation, nowadays under the ward of University of South California, duly renamed as the USC Shoah Foundation Institute for Visual History and Education. The thesis that will be defended here is the one that even Terror's memory and testimony can be aestheticized and absorbed by the cultural goods market, in a sanitized and consoling format, liable of being consumed for a potentially massive audience. Regarding good intentions - if such exists -, Steven Spielberg configures himself as an arguable "authority" media-wise - related to the Holocaust, conforming the western imaginary about the memory of the genocide through his Foundation and the prior success of the film Schindler's list (1993).

\section{Key-words:}

Testimony. Consumption culture. Holocaust. Survivors of the Shoah. Steven Spielberg.
Cómo consumir - con placer estético - los testimonios del Holocausto: una evaluación crítica sobre la fundación Survivors of the Shoah

\section{Resumen}

El presente artículo reflexiona acerca del estatuto del testimonio del Holocausto judío en el ámbito de una cultura de consumo, teniendo como objeto de análisis el proyecto original de Steven Spielberg, Survivors of the Shoah, Visual History Fundation, hoy bajo la custodia de la Universidad de California del Sur, debidamente rebautizado de USC Shoah Fundation Institute for Visual History and Education. Defenderemos la tesis de que el propio testimonio y la memoria del Terror pueden ser estetizados y absorbidos por el mercado de bienes culturales, en un formato saneado y consolador, pasible de ser consumido por un público potencialmente masivo. En que pesen las buenas intenciones - si es que existen -, Steven Spielberg se configura como una discutible "autoridad" - de los medios de comunicación - en relación al Holocausto, conformando el imaginario occidental sobre la memoria del genocidio con su fundación y el éxito anterior de la película La lista de Schindler (1993).

\section{Palabras-Clave}

Testimonio. Cultura de Consumo. Holocausto. Survivors of the Shoah. Steven Spielberg. 


\section{Expediente}

A revista E-Compós é a publicação científica em formato eletrônico da Associação Nacional dos Programas de Pós-Graduação em Comunicação (Compós). Lançada em 2004, tem como principal finalidade difundir a produção acadêmica de pesquisadores da área de Comunicação, inseridos em instituições do Brasil e do exterior.
E-COMPÓS I www.e-compos.org.br I E-ISSN 1808-2599

Revista da Associação Nacional dos Programas de Pós-Graduação em Comunicação. Brasília, v.13, n.2, maio/ago. 2010

A identificação das edições, a partir de 2008 passa a ser volume anual com três números.

\section{CONSELHO EDITORIAL}

Afonso Albuquerque

Universidade Federal Fluminense, Brasil

Alberto Carlos Augusto Klein

Universidade Estadual de Londrina, Brasi

Alex Fernando Teixeira Primo

Universidade Federal do Rio Grande do Sul, Brasil

Alfredo Vizeu

Universidade Federal de Pernambuco, Brasi

Ana Carolina Damboriarena Escosteguy

Pontifícia Universidade Católica do Rio Grande do Sul, Brasil

Ana Silvia Lopes Davi Médola

Universidade Estadual Paulista, Brasil

André Luiz Martins Lemos

Universidade Federal da Bahia, Brasil

Ângela Freire Prysthon

Universidade Federal de Pernambuco, Brasil

Antônio Fausto Neto

Universidade do Vale do Rio dos Sinos, Brasil

Antonio Carlos Hohlfeldt

Pontifícia Universidade Católica do Rio Grande do Sul, Brasil

Arlindo Ribeiro Machado

Universidade de São Paulo, Brasil

César Geraldo Guimarães

Universidade Federal de Minas Gerais, Brasil

Cristiane Freitas Gutfreind

Pontifícia Universidade Católica do Rio Grande do Sul, Brasil

Denilson Lopes

Universidade Federal do Rio de Janeiro, Brasil

Eduardo Peñuela Cañizal

Universidade Paulista, Brasi

Erick Felinto de Oliveira

Universidade do Estado do Rio de Janeiro, Brasil

Francisco Menezes Martins

Universidade Tuiuti do Paraná, Brasil

Gelson Santana

Universidade Anhembi/Morumbi, Brasil

Goiamérico Felício

Universidade Federal de Goiás, Brasil

Hector Ospina

Universidad de Manizales, Colômbia

Herom Vargas

Universidade Municipal de São Caetano do Sul, Brasil

leda Tucherman

Universidade Federal do Rio de Janeiro, Brasil

Itania Maria Mota Gomes

Universidade Federal da Bahia, Brasil

Janice Caiafa

Universidade Federal do Rio de Janeiro, Brasil

Jeder Silveira Janotti Junior

Universidade Federal da Bahia, Brasil

João Freire Filho

Universidade Federal do Rio de Janeiro, Brasil

John DH Downing

University of Texas at Austin, Estados Unidos

José Luiz Aidar Prado

Pontifícia Universidade Católica de São Paulo, Brasil

José Luiz Warren Jardim Gomes Braga

Universidade do Vale do Rio dos Sinos, Brasil

Juremir Machado da Silva

Pontifícia Universidade Católica do Rio Grande do Sul, Brasil

Lorraine Leu

University of Bristol, Grã-Bretanha

Luiz Claudio Martino

Universidade de Brasília, Brasil

Maria Immacolata Vassallo de Lopes

Universidade de São Paulo, Brasil

Maria Lucia Santaella

Pontifícia Universidade Católica de São Paulo, Brasil

Mauro Pereira Porto

Tulane University, Estados Unidos

Muniz Sodre de Araujo Cabral

Universidade Federal do Rio de Janeiro, Brasil

Nilda Aparecida Jacks

Universidade Federal do Rio Grande do Sul, Brasil

Paulo Roberto Gibaldi Vaz

Universidade Federal do Rio de Janeiro, Brasil

Renato Cordeiro Gomes

Pontifícia Universidade Católica do Rio de Janeiro, Brasil

Ronaldo George Helal

Universidade do Estado do Rio de Janeiro, Brasil

Rosana de Lima Soares

Universidade de São Paulo, Brasil

Rossana Reguillo

Instituto Tecnológico y de Estudios Superiores do Occidente, México

Rousiley Celi Moreira Maia

Universidade Federal de Minas Gerais, Brasil

Samuel Paiva

Universidade Federal de São Carlos, Brasil

Sebastião Albano

Universidade Federal do Rio Grande do Norte, Brasil

Sebastião Carlos de Morais Squirra

Universidade Metodista de São Paulo, Brasil

Simone Maria Andrade Pereira de Sá

Universidade Federal Fluminense, Brasi

Suzete Venturelli

Universidade de Brasília, Brasil

Valério Cruz Brittos

Universidade do Vale do Rio dos Sinos, Brasil

Veneza Mayora Ronsini

Universidade Federal de Santa Maria, Brasil

Vera Regina Veiga França

Universidade Federal de Minas Gerais, Brasi

\section{COMISSÃO EDITORIAL}

Felipe da Costa Trotta I Universidade Federal de Pernambuco, Brasil Rose Melo Rocha I Escola Superior de Propaganda e Marketing, Brasil Adriana Braga I Pontificia Universidade Católica do Rio de Janeiro, Brasil CONSULTORES AD HOC

Roseli Figaro I Universidade de São Paulo, Brasil

Miguel Serpa Pereira I Pontifícia Universidade Católica do Rio de Janeiro, Brasil João Maia I Universidade do Estado do Rio de Janeiro, Brasil

Paulo Cunha Filho I Universidade Federal de Pernambuco, Brasil Benjamim Picado I Universidade Federal Fluminense, Brasi Josimey Silva I Universidade Federal do Rio Grande do Norte, Brasil REVISÃO DE TEXTO E TRADUÇÃo I Everton Cardoso EDITORAÇÃo ELETRÔNICA I Roka Estúdio
COMPOS I wWw.compos.org.br

Associação Nacional dos Programas de Pós-Graduação em Comunicação

Presidente

Itania Maria Mota Gomes

Universidade Federal da Bahia, Brasil

itania@ufba.br

Vice-presidente

Julio Pinto

Pontifícia Universidade Católica de Minas Gerais, Brasil juliopinto@pucminas.br

Secretária-Geral

Ana Carolina Escosteguy

Pontifícia Universidade Católica do Rio Grande do Sul, Brasil carolad@pucrs.br 